\section{Risky sexual practices among men who have sex with men in Northeast Brazil: results from four sequential surveys}

\author{
Práticas sexuais de risco de homens que fazem \\ sexo com homens no Nordeste do Brasil: \\ resultados de quatro inquéritos seqüenciais
}

\footnotetext{
1 Grupo de Apoio à Prevenção à AIDS/Ceará, Fortaleza,

Brasil.

2 Departamento de Saúde Comunitária, Universidade Federal do Ceará, Fortaleza, Brasil.

3 Instituto de Medicina

Social, Universidade do

Estado do Rio de Janeiro, Rio

de Janeiro, Brasil.

4 Departamento de

Psicologia, Universidade

Federal do Ceará, Fortaleza,

Brasil.

5 Department of

International Health and

Development, Tulane

University, New Orleans,

U.S.A.

\section{Correspondence}

L. R. F. S. Kerr

Departamento de Saúde

Comunitária, Universidade

Federal do Ceará

Rua Prof. Costa Mendes

1608, 5o andar, Fortaleza, CE

60190-080, Brasil.

ligia@ufc.br
}

\section{Abstract}

This paper focuses on recent trends in risky sexual practices for HIVIAIDS among men who have sex with men (MSM) in Fortaleza, Ceará State, Brazil. Four cross-sectional surveys were conducted (1995, 1998, 2002, and 2005) among MSM 14 years or older who reported oral or anal sex in the previous 12 months. Sexual practices were considered risky whenever the respondent reported unprotected receptive or insertive anal intercourse in the six months preceding the interview. Different selection techniques were used to recruit the study population: snowball (1995, 1998, $2002-32 \%)$; time-space sampling (2002-68\%); and respondent-driven sampling (2005). Analyses were based on the comparison between proportions. High rates of risky sexual practices were reported in 1995 (49.9\%), decreasing in 1998 (32.6\%), increasing again in 2002 (51.3\%), and showing the lowest level in 2005 (31.4\%). Participants with more schooling increased their risky practices from 1998 to 2002, decreasing in 2005. Among individuals with medium or low schooling, risky behavior declined from 2002 to 2005. The article highlights the need for behavioral surveillance to properly address STD/HIV prevention.

Sexual Behavior; Unsafe Sex; Male Homosexuality

\author{
Rogério Costa Gondim 1 \\ Ligia Regina Franco Sansigolo Kerr ${ }^{2}$ \\ Guilherme L. Werneck 3 \\ Raimunda Hermelinda Maia Macena 1 \\ Marta Kerr Pontes 4 \\ Carl Kendall 5
}

\section{Introduction}

In Brazil, AIDS cases among men who have sex with men (MSM) predominated as a proportion of the total number of reported cases for many years. However, the early 1990s witnessed a relative decrease in this category along with a proportional increase of cases in heterosexuals 1,2,3. In the Northeast Region, AIDS cases among men who have sex with men still represent a considerably high proportion, with some $50 \%$ of all cases reported in recent years 4 .

It is essential to study the variation in sexual behavior among MSM over time and in relation to their attitudes and practices, as well as to determine the associated factors, in order to draft more adequate preventive strategies 5,6.

Cross-sectional studies on sexual behavior have been recommended to monitor populations at increased risk of HIV infection 5,7. This process consists of the systematic repetition of cross-sectional studies or behavioral surveillance surveys (BSS) ${ }^{8}$ capable of analyzing behaviors, knowledge, and attitudes related to HIV/AIDS and other sexually transmitted diseases (STDs) 5,9,10. The main purpose of these studies is to detect the behavior changes in the most vulnerable population groups that can have the greatest impact on the AIDS epidemic. Such studies can also be useful to detect behavioral time trends in regions exposed to prevention work, thus serving as an important compo- 
nent for evaluating and monitoring such activities $6,7,11,12$.

Monitoring behavior through cross-sectional studies is considered essential for the epidemiological surveillance of HIV/AIDS and other STDs $5,7,13$. Such surveys can be used for evaluation, in combination with qualitative methodologies, especially in a triangulation process, and in the choice of sentinel groups based on epidemiological, political, and cultural aspects. A two-year interval is recommended between the survey waves in order to detect behavioral trends that provide the basis for adjustments in prevention programs 5,8,10,14. Different methodologies have been used to monitor hard-toreach populations, including the snowball technique, time-space sampling, and more recently respondent-driven sampling.

Snowball sampling is a non-probabilistic selection procedure in which an initial group of members of the target population identifies other potential participants, and so on successively 15,16 . Despite the gain in efficiency in the identification and inclusion of members of hard-to-reach populations, the procedure frequently falls short of a representative sample of the target population, due to the tendency of individuals to name persons with similar social, demographic, and behavioral characteristics. Time-space sampling (TSS) seeks to emulate a probabilistic sample by mapping the universe of sites where a large number of members of the target population can be found. Random samples of days, times, and recruiting sites are conducted, and potential participants are systematically selected at these sites 17,18,19. However, TSS only includes populations that normally frequent the selected sites. A method that was developed more recently, called respondentdriven sampling (RDS), offers more statistical rigor in relation to the snowball selection process, through the use of longer recruiting chains, limits to recruitment, and collection of data that can be used to adjust for possible biases inherent to the process by which individuals with similar characteristics form contact networks and are more prone to recruit each other 20,21 . However, despite increasing use in surveys to identify hard-to-reach populations, as a methodology RDS is still under development, and some statistical issues remain to be clarified 22 .

The aim of the current study is to analyze the behavior of MSM in different time periods in the municipality of Fortaleza, in order to support possible changes in AIDS prevention strategies in this specific population in the State of Ceará, Brazil.

\section{Material and methods}

\section{Study type and site}

Four cross-sectional surveys were conducted in the municipality of Fortaleza, capital of the State of Ceará in Northeast Brazil. Fortaleza is one of the country's five largest cities (Instituto Brasileiro de Geografia e Estatística; http://www.ibge.gov.br), characterized by major social inequality, and with tourism as one of its main sources of income.

\section{Study population}

The study population consisted of MSM, 14 years or older, living in Fortaleza, who reported having practiced oral or anal sex with men in the previous 12 months.

In 1995, 400 men were recruited, $65 \%$ of whom through the snowball technique 15,$23 ; 15 \%$ in public places; $9 \%$ in bars or nightclubs; and $11 \%$ in other places such as movie theaters, saunas, beaches, workplaces, and nongovernmental organizations (NGOs). In 1998, 100\% of the 200 participants were recruited with the snowball technique. In 2002, the sample of 401 men was based on two sampling techniques: snowball (32\% of participants) and TSS (68\%) 12,17,18. In 2005, 406 men were recruited using RDS 20,24. Each year the recruitment sites were mapped with the help of NGOs that work in AIDS prevention in the MSM population or leaders of the gay community.

\section{Data collection and study variables}

A semi-structured KAP questionnaire (knowledge, attitudes, and practices) was applied, seeking comparability with standard questions recommended for this type of population and that had already been used in previous surveys in this State, in other studies by the Ministry of Health, and in international studies 5,7 .

Interviews were conducted by previously trained interviewers, selected among MSM who assumed their homosexual/bisexual orientation, had some research or survey experience, and showed interest in participating in the study. The choice of interviewers with the same characteristics as the sample aimed to facilitate their access to the target group and the gay settings where the interviews were held. Questionnaires were applied over the course of two months in 1995, three months each in 1998 and 2002, and six weeks in 2005.

Subjects were asked about the following: age ( $<25$ and $\geq 25$ years), schooling (illiterate/incomplete primary schooling, complete primary 
schooling, and complete secondary or greater), sexual identity (gay, man/bofe, bisexual, and other), pattern of sexual relations in previous six months (no sexual relations, steady relationship with a man and with no sex with other men, steady relationship with a man and sex with other men, casual sex with different men). Risky sexual behavior or practice was defined as any insertive or receptive anal intercourse without condoms in the six months prior to the interview.

\section{Data analysis}

Prevalence rates for risky sexual behavior or practice were calculated in relation to the study variables and respective 95\% confidence intervals $(95 \% \mathrm{CI})$ for all the years studied. These measures were chosen because the software used in the RDS methodology calculates these parameters, adjusted for the size of the participants' social network and the way the participants were recruited. To evaluate time trends, data for each year were compared to those for the immediately following year.

Stata 9.0 (Stata Corp., College Station, USA) was used to process the data for 1995, 1998, and 2002, and RDSAT 5.5.0 (Volz E, Wejnert C, Degani I, Heckathorn DD. Cornell University, Ithaca,
USA) for 2005, in the latter case adjusting for the design effects. Calculation of the differences in proportions of sexual practices used the Pearson $\chi^{2}$ and $95 \% \mathrm{CI}$.

\section{Ethical issues}

The research project was approved by the Institutional Review Board of the São José Hospital for Infectious Diseases in Fortaleza for the years prior to 2005 and the Institutional Review Board of the Federal University in Ceará for 2005. All subjects were informed of the study's objectives and signed a free and informed consent form.

\section{Results}

The percentage of MSM involved in risky sex practices differed significantly between years. The proportion was high in 1995 (49.9\%), decreasing significantly in 1998 (32.6\%), increasing again in 2002 (54.6\%), and reaching the lowest level in 2005 (31.4\%) (Figure 1). This same pattern was observed in the two age brackets studied.

The percentage of MSM at risk varied significantly according to schooling. Individuals with more schooling were involved more frequently

Figure 1

Proportion of men who have sex with men (MSM) at risk. Fortaleza, Ceará State, Brazil, 1995 to 2005

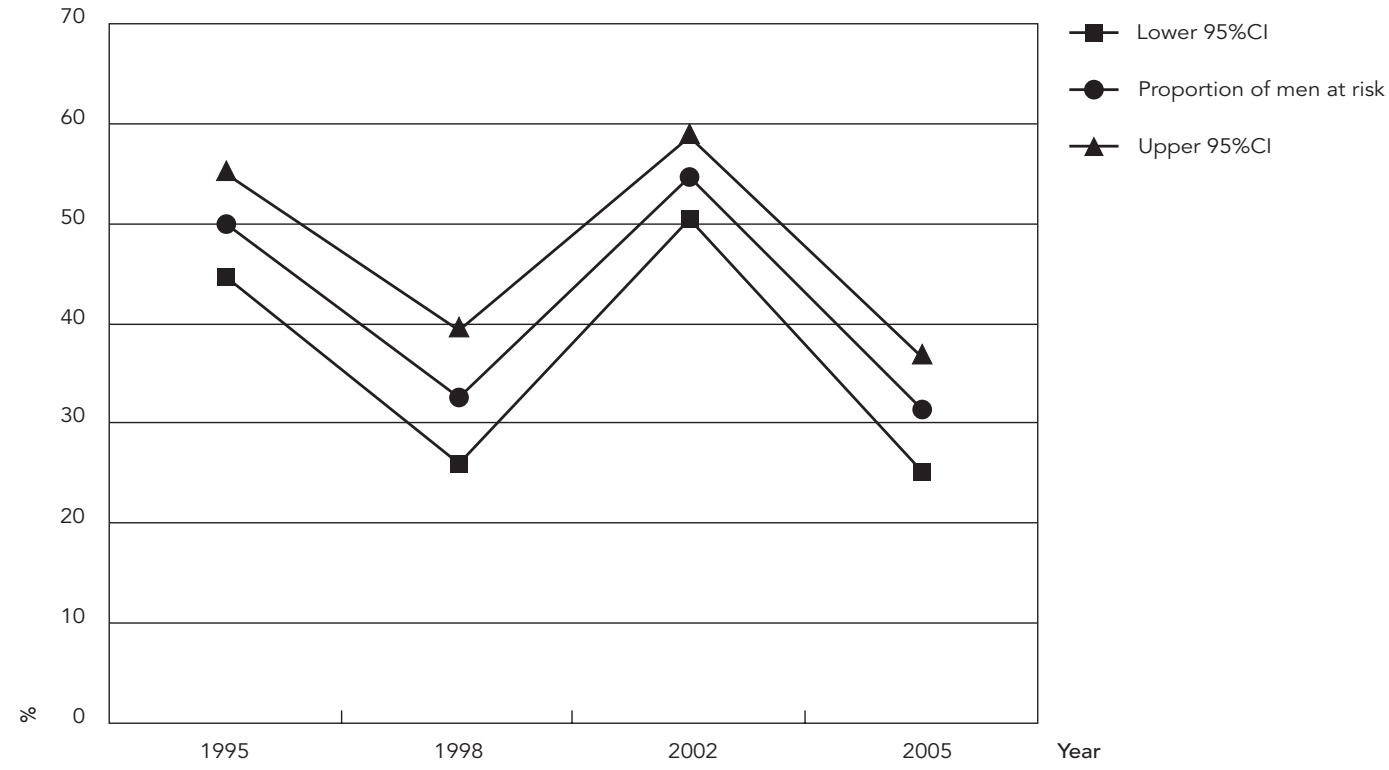


in unsafe sex practices in $2002(44.3 \%)$ as compared to 1998 (28.7\%). However, this proportion showed an important decline in 2005 , to $21 \%$. Meanwhile, subjects with low or medium schooling only showed a significant drop in risky behavior from 2002 (90.5\% - low; $67.6 \%$ - medium) to 2005 (29.1\% - low; $34.3 \%$ - medium) (Table 1 and Figure 2).

The proportion of MSM involved in risky sexual practices did not vary substantially according to sexual identity. Significant temporal variations were only observed in relation to gay sexual identity: there was a significant increase in gay men involved in risky sexual practices from 1998 (34.6\%) to 2002 (52.5\%), with a decline in the last year (35.8\%) (Table 1).

Considering only participants that reported sexual relations in the previous six months, having a steady partner and no sex with other men, i.e., a so-called monogamous relationship, decreased from approximately $38 \%$ in 1995 and 1998 to some $30 \%$ in the subsequent years. Having a steady partner that and having sex with other men remained relatively constant throughout the period. Casual sex with different partners increased over the period, surpassing $50 \%$ in 2005 .
Involvement in risky sexual relations showed important variations over time when comparing the different patterns of sexual relationships. Within so-called monogamous relationships, there was a decrease in unsafe sex from 2002 (56.4\%) to 2005 (26.3\%). For a steady relationship with a partner and sex with other men, the risk remained high throughout the period, with no significant variations. Among individuals that reported casual relations with different men, the risk pattern followed the same overall trend as in the target population as a whole (Table 1).

\section{Discussion and conclusions}

Sexual behavior and practices by MSM in Fortaleza varied significantly over the period, as in similar studies in the United States, Australia, and Great Britain 6,25,26. Several factors could be associated with this fluctuating behavior.

Heavy funding constraints for AIDS prevention in Brazil since several international agencies have curtailed their cooperation in the country and focused elsewhere (e.g., Africa and Eastern Europe) may help explain the fluctuating trends in risky sexual practices observed in the current

Figure 2

Proportion of men who have sex with men (MSM) at risk according to level of schooling. Fortaleza, Ceará State, Brazil, 1995 to 2005.

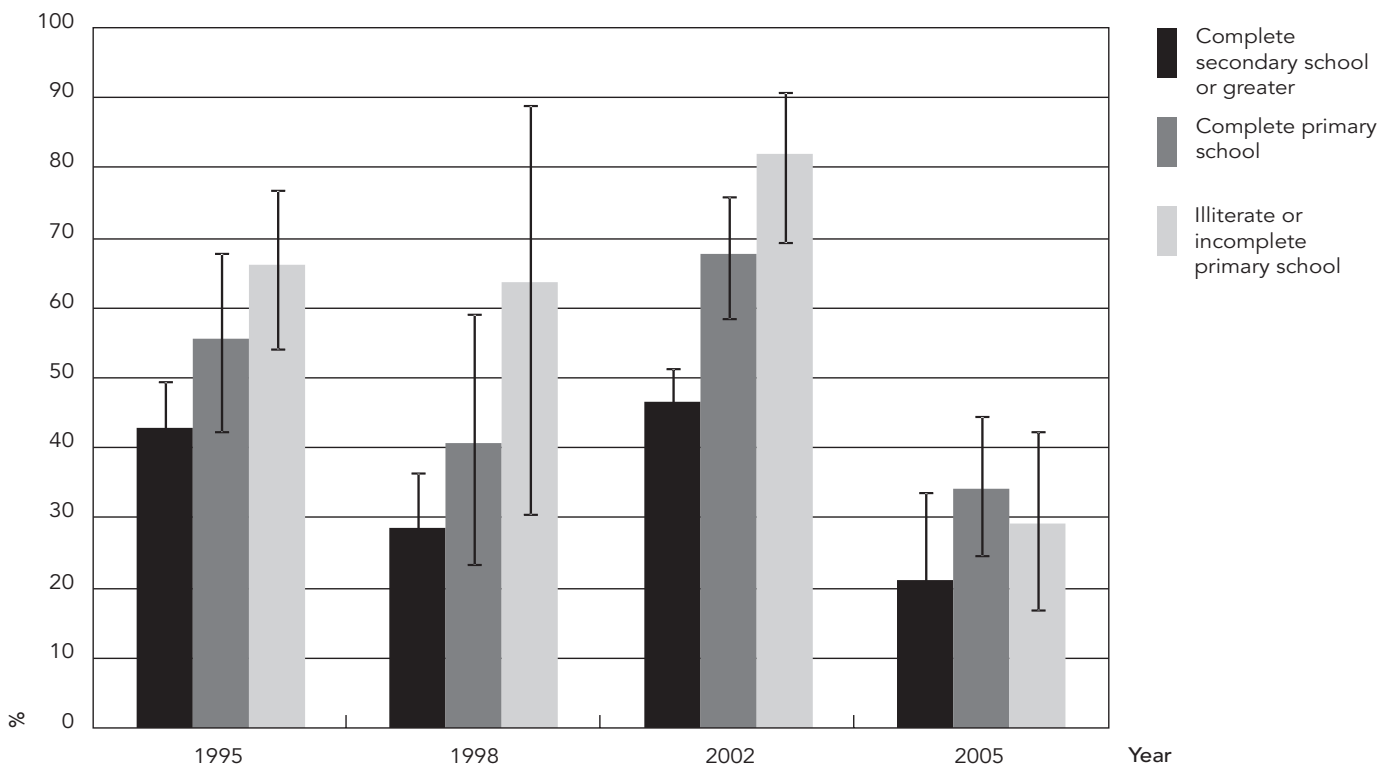


Socioeconomic characteristics of men who have sex with men (MSM). Fortaleza, Ceará State, Brazil, 1995 to 2005.

\begin{tabular}{|c|c|c|c|c|c|c|c|c|}
\hline \multirow[t]{3}{*}{ Variables } & \multicolumn{2}{|c|}{1995} & \multicolumn{2}{|c|}{1998} & \multicolumn{2}{|c|}{2002} & \multicolumn{2}{|c|}{2005} \\
\hline & \multicolumn{2}{|c|}{ Men at risk } & \multicolumn{2}{|c|}{ Men at risk } & \multicolumn{2}{|c|}{ Men at risk } & \multicolumn{2}{|c|}{ Men at risk * } \\
\hline & n (\%) & $95 \% \mathrm{Cl}$ & n (\%) & $95 \% \mathrm{Cl}$ & n (\%) & $95 \% \mathrm{Cl}$ & n (\%) & $95 \% \mathrm{Cl} * *$ \\
\hline \multicolumn{9}{|l|}{ Age (years) } \\
\hline$<25$ & $130(53.1)$ & $44.1-61.9$ & $61(32.8)$ & $21.3-46.0$ & $127(59.8)$ & $50.8-68.4$ & $190(35.2)$ & $24.5-45.0$ \\
\hline$\geq 25$ & $239(48.1)$ & $41.6-54.7$ & $132(32.6)$ & $24.7-41.3$ & $251(46.6)$ & $40.3-53.0$ & $214(27.4)$ & $20.8-37.3$ \\
\hline \multicolumn{9}{|l|}{ Schooling } \\
\hline \multicolumn{9}{|l|}{ Complete secondary } \\
\hline school or greater & $231(42.9)$ & $36.4-49.5$ & $150(28.7)$ & $21.6-36.6$ & $289(44.3)$ & $38.4-50.2$ & $205(21.0)$ & 13.4-33.9 \\
\hline \multicolumn{9}{|l|}{ Complete primary or } \\
\hline incomplete secondary & $63(55.6)$ & $42.5-68.1$ & $32(40.6)$ & $23.7-59.4$ & $71(67.6)$ & $55.5-78.2$ & $91(34.3)$ & $24.7-44.8$ \\
\hline \multicolumn{9}{|l|}{ Illiterate/Incomplete } \\
\hline primary & $74(66.2)$ & $54.2-76.8$ & $11(63.6)$ & $30.8-89.1$ & $21(90.5)$ & 69.6-98.9 & $92(29.1)$ & $17.0-42.4$ \\
\hline \multicolumn{9}{|l|}{ Identity } \\
\hline Gay & $268(47.8)$ & $41.6-53.9$ & $162(34.6)$ & $27.3-42.4$ & $297(52.5)$ & $46.7-58.3$ & $258(35.8)$ & $25.1-43.6$ \\
\hline Man/Bofe & $22(59.1)$ & $36.4-79.3$ & $9(22.2)$ & $2.8-60.0$ & $16(43.8)$ & $19.8-70.1$ & $46(23.6)$ & $11.4-40.6$ \\
\hline Bisexual & $57(47.4)$ & $34.0-61.0$ & $20(25.0)$ & $8.7-49.1$ & $55(45.5)$ & $32.0-59.4$ & $94(25.3)$ & $13.8-36.8$ \\
\hline Other & $21(71.4)$ & $47.8-88.7$ & $2(0.0)$ & $0.0-84.2$ & $8(50.0)$ & $15.7-84.3$ & $4(81.0)$ & $0.0-99.9$ \\
\hline \multicolumn{9}{|c|}{ Pattern of sexual relationship } \\
\hline \multicolumn{9}{|l|}{ (six months) } \\
\hline \multicolumn{9}{|c|}{ Steady with one man, without } \\
\hline sex with other men & $108(59.3)$ & $49.4-68.6$ & $63(36.5)$ & $24.7-49.6$ & $101(56.4)$ & $46.2-66.3$ & $103(26.3)$ & $16.9-40.7$ \\
\hline \multicolumn{9}{|c|}{ Steady with one man, with } \\
\hline sex with other men & $49(57.1)$ & $42.2-71.2$ & $32(50.0)$ & $31.9-68.1$ & $78(62.8)$ & $51.1-73.5$ & $46(49.5)$ & $34.3-65.8$ \\
\hline \multicolumn{9}{|l|}{ Casual relations with } \\
\hline different men & $132(47.7)$ & $39.0-56.6$ & $71(23.9)$ & $14.6-35.5$ & $178(43.8)$ & $36.4-51.4$ & $179(25.2)$ & $6.6-42.9$ \\
\hline
\end{tabular}

* Percentage adjusted by RDSAT 5.5.0 (Volz E, Wejnert C, Degani I, Heckathorn DD. Cornell University, Ithaca, USA);

** Overlapping intervals were interpreted as not showing a statistically significant difference.

study 27,28. Thus, Brazil had to prioritize more vulnerable population segments like women and children (to prevent vertical transmission). This decline in funding particularly impacted AIDS and STD prevention in the male homosexual and bisexual community, especially from 1998 to 2002. Specifically, the year 2002 showed the highest proportion of risky sexual practices in this community, which had shown decreases in unsafe sex practices until 1998.

Strides in AIDS treatment may also help explain the fluctuations in the percentage of MSM practicing unsafe sex during this period. The emergence of new and more effective drugs has made AIDS a "controllable" disease, improving quality of life, increasing survival 29,30, while also leading to a feeling of greater safety in unprotected sexual practices 31,32 . Various studies contend that the observed increase in risky practices in some developed countries around 2002 6,33,34,35 resulted from the reappearance of individuals willing to have unsafe sex as a function of the decline in morbidity and mortality due to highly active antiretroviral therapy (HAART) 2,11,36,37. It is also possible that a new generation of adolescents with homosexual orientation feel the desire for a more intimate sexual experience at some time in their lives, without mechanical barriers $38,39,40,41$.

Level of schooling was also an important factor associated with involvement in unsafe sex. From 1995 to 2002, individuals with less schooling were exposed to greater risk, apparently not having been reached by the safe sex campaigns implemented mainly from 1995 to 1998. Meanwhile, higher schooling alone appeared as a protective factor throughout the entire period, probably due to greater access to information, independently of government and nongovernmental action 42,43. Yet even more educated individuals showed a high rate of risky practices, especially after a period with- 
out major prevention work in this community (1998 to 2002).

Various studies suggest that pattern of sexual relationship may be associated with risky sexual behavior. For example, some authors emphasize that condom use in steady relations tends to be lower 44,45, a phenomenon corroborated in a survey on sexual behavior in the Brazilian population $46,47,48$. This is associated with the belief that condoms are a valid preventive measure 49 , but that they are unnecessary when one "knows the partner intimately" 50,51. The international literature also suggests that when an individual begins a steady relationship, the other previous "steady partners" are not taken into account. Equally common among MSM and other groups (e.g., adolescents) is the occurrence of "serial monogamy" 49,52,53, whereby steady relations with a single partner for a relatively short period are followed by other relationships with the same characteristics. This leads to the unsubstantiated belief that unprotected sex is safe against STD/ AIDS in such situations.

However, it does not appear that the changes in the pattern of sexual relations among Brazilian MSM over the course of the period studied here can explain the observed fluctuations. There was in fact a decline in steady sexual relations without sex with other partners from 1998 to 2002, a substantial increase in casual relations in the last wave, and relative stability in the percentage of MSM reporting steady relations combined with sex with other men, but the fluctuations in risky behaviors do not follow any consistent trend with variations in the patterns of sexual relationships.

This was a pioneering study in monitoring sexual behavior and involvement in unsafe sex practices for STD/AIDS among MSM in the State of Ceará and Brazil as a whole. Epidemiological studies on such issues are essential for adequate surveillance of the AIDS epidemic, since surveillance of HIV alone is known to be insufficient to provide information for planning preventive measures 5 . This type of follow-up is known as second-generation HIV surveillance 8,54. This monitoring strategy is capable of gathering important information on the diversity of behaviors and sexual practices among MSM and other potentially hidden or hard-to-reach populations 18,55 .

The surveys presented here summarize some of the main problems in studies targeting hardto-reach populations, and there is generally no single solution, since comparisons with results obtained using an ideal selection process (e.g., censuses of these populations) are not feasible. There is extensive international literature using these different types of sampling, and the vast majority use analytical procedures as if these processes were derived from random samples. In the years preceding 2005, the same approach was taken to the samples, regardless of the sampling technique used. The majority of the studies using TSS were non-weighted, and there is still considerable debate over the most appropriate methods for weighting and adjusting the samples obtained via TSS and RDS.

Sequential studies of MSM are still quite scarce in Brazil and even in the international setting. Most of the existing studies used other sampling techniques cited in this study until 2005, when the RDS methodology began to be used in the country and was recommended by the Ministry of Health as the method of choice for hard-toreach populations in general. In 2002, when TSS was used, there was little experience in Brazil on the weighting used to analyze data collected with this technique. Although participants in the 2002 study were selected randomly, it was not possible to weight them, since the data were lost on the total number of individuals from which the sample was extracted. Thus, while recognizing the limitation of the processes used in this study, there is no other study like it in Brazil.

The results of the current study should be interpreted in light of the familiar limitations of non-probabilistic selection procedures and particularly the use of different methodologies from one study year to the next. One must consider the possibility that these characteristics accounted at least partially for the time trends indicated here. However, a study comparing populations recruited with the different methodologies showed that the participants are distributed in different proportions in the social classes, leading to overrepresentation of higher-income individuals with the TSS and snowball techniques and their under-representation in RDS 56. Thus, the decrease in risky behavior observed in 2005 would gain even more validity, given the greater participation by lower-income social classes, which usually show higher rates of risky behavior.

Brazil demonstrates a high degree of geographic, social, economic and cultural heterogeneity, and local policies need to take this into account. This is true both at the government level and in the development of civil society organizations involved in the response to AIDS 57. Thus, when studying risky sexual behaviors, some important issues should be considered, especially the fact that subjective characteristics are involved in the problem. In this sense, there is an evident need to understand the sexual values in Brazilian culture in general, and more specifically in the homosexual subcultures, considering the subjective aspects related to erotic pleasure and 
sexual satisfaction, which are associated with risky behaviors and the difficulties in changing them, regardless of the population's knowledge of risky practices 36 .

Thus, prevention and intervention activities are needed that extend beyond supplying infor- mation. These interventions need to understand and address the more complex social and psychological issues associated with risky sexual practices, since the adoption of safer practices is not necessarily related to the level of knowledge about them.

\section{Resumo}

Estudaram-se as tendências recentes das práticas sexuais de risco para DST/AIDS entre homens que fazem sexo com homens (HSH) em Fortaleza, Ceará, Brasil. Realizaram-se quatro estudos seccionais (1995, 1998, 2002 e 2005) em HSH, com 14 anos ou mais, que tenham referido prática sexual oral ou anal com homens nos últimos 12 meses. Definiu-se prática sexual de risco uma relação anal insertiva ou receptiva sem uso de preservativo nos seis meses que antecederam a entrevista. Utilizaram-se técnicas de recrutamento do tipo snow ball (1995, 1998, $2002-32 \%)$; time space sampling (2002-68\%) $e$ respondent driven sampling (2005). Análises basearam-se nas comparações entre proporções. Elevados percentuais de práticas sexuais de risco foram referidos em 1995 (49,9\%), decrescendo em 1998 (32,6\%), crescendo em 2002 (51,3\%) e apresentando os menores percentuais em 2005 (31,4\%). Indivíduos com escolaridade mais elevada aumentaram as práticas de risco entre 1998 e 2002, decrescendo no último período. Nos de estrato de escolaridade baixa ou média observou-se declínio no comportamento de risco entre 2002 e 2005. Os resultados deste estudo salientam a importância da vigilância comportamental para adequação dos programas de prevenção das DST/ AIDS nessa população.

Comportamento Sexual; Sexo sem Proteção; Homossexualidade Masculina

\section{Contributors}

R. C. Gondim participated in the elaboration of the projects in the different years, the fieldwork from 1995 to 2002, data analysis, and writing of the article. L. R. F. S. Kerr contributed to the elaboration of the projects in the different years, the data analysis, and writing of the article. G. L. Werneck contributed to the data analysis and writing and revision of the article. R. H. M. Macena and M. K. Pontes collaborated in the fieldwork in 2005, the data analysis, and writing of the article. C. Kendall participated in the data analysis and writing of the article.

\section{Acknowledgments}

The authors wish to thank the Coordinating Agency for Graduate Studies (CAPES, Research Projects PROCAD 0119/01-6 and 0204/05-6) for funding the exchange among researchers from the different institutions; the Ceará State Research Foundation (FUNCAP) for the PhD scholarship for Rogério Costa Gondim; the National STD/AIDS Program (PN-DST/AIDS) under the Brazilian Ministry of Health for research funding in 1995; the Ceará State Health Secretariat for research funding in 1998 and 2002; and CDC/GAP-Brazil, the process of which was coordinated by the PN-DST/AIDS, for the research funding in 2005. 


\section{References}

1. Brito AM, Castilho EA, Szwarcwald CL. AIDS e infecção pelo HIV no Brasil: uma epidemia multifacetada. Rev Soc Bras Med Trop 2001; 34:207-17.

2. Dourado I, Veras MASM, Barreira D, de Brito AM. Tendências da epidemia de AIDS no Brasil após a terapia anti-retroviral. Rev Saúde Pública 2006; 40 Suppl:9-17.

3. Szwarcwald CL, Bastos FI, Esteves MAP, Andrade CLT. A disseminação da epidemia da AIDS no Brasil, no período de 1987-1996: uma análise espacial. Cad Saúde Pública 2000; 16 Suppl 1:7-19.

4. Almeida RLC. Distribuição espacial da AIDS no município de Fortaleza e seus determinantes sócio-econômicos [Masters Thesis]. Fortaleza: Universidade Federal do Ceará; 2001.

5. Amon J, Brown T, Hogle J, MacNeil J, Magnani $\mathrm{R}$, Mills S, et al. Behavioral Surveillance Surveys (BSS): guidelines for repeated behavioral surveys in population at risk of HIV. http://www.fhi.org/ en/topics/bss.htm (accessed on 08/Oct/2008).

6. Williamson LM, Dodds JP, Mercey DE, Johnson AM, Hart GJ. Increases in HIV-related sexual risk behavior among community samples of gay men in London and Glasgow: how do they compare? J Acquir Immune Defic Syndr 2006; 42:238-41.

7. Henry K. BSS: Tracking trends in sexual behavior. Aidscaptions 1996; 3:33.

8. Rehle T, Lazzari S, Dallabetta G, Samoah-Odei E. Second generation HIV surveillance: better data for decision-making. Bull World Health Organ 2004; 82:121-7.

9. Mills S, Benjarattanaporn P, Bennett A, Pattalung RN, Sundhagul D, Trongsawad P, et al. HIV risk behavioral surveillance in Bangkok, Thailand: sexual behavior trends among eight population groups. AIDS 1997; 11 Suppl 1:S43-51.

10. Mills S, Saidel T, Bennett A, Rehle T, Hogle J, Brown T, et al. HIV risk behavioral surveillance: a methodology for monitoring behavioral trends. AIDS 1998; 12 Suppl 2:S37-46.

11. Boily MC, Bastos FI, Desai K, Masse B. Changes in the transmission dynamics of the HIV epidemic after the wide-scale use of antiretroviral therapy could explain increases in sexually transmitted infections: results from mathematical models. Sex Transm Dis 2004; 31:100-13.

12. Pollack LM, Osmond DH, Paul JP, Catania JA. Evaluation of the Centers for Disease Control and Prevention's HIV behavioral surveillance of men who have sex with men: sampling issues. Sex Transm Dis 2005; 32:581-9.

13. Martin JL. AIDS risk reduction recommendations and sexual behavior patterns among gay men: a multifactorial categorical approach to assessing change. Health Educ Q 1986; 13:347-58.

14. MacLachlan EW, Baganizi E, Bougoudogo F, Castle S, Mint-Youbba Z, Gorbach P, et al. The feasibility of integrated STI prevalence and behaviour surveys in developing countries. Sex Transm Infect 2002; 78:187-9

15. Biernacki P, Waldorf D. Snowball sampling. Problems and techniques of chain referral sampling. Sociol Methods Res 1981; 10:141-63.
16. Erickson BH. Some problems of inference from chain data. Sociol Methodol 1979; 10:276-302.

17. Muhib FB, Lin LS, Stueve A, Miller RL, Ford WL, Johnson WD, et al. A venue-based method for sampling hard-to-reach populations. Public Health Rep 2001; 116 Suppl 1:216-22.

18. Stueve A, O'Donnell LN, Duran R, San DA, Blome J. Time-space sampling in minority communities: results with young Latino men who have sex with men. Am J Public Health 2001; 91:922-6.

19. Magnani R, Sabin K, Saidel T, Heckathorn D. Review of sampling hard-to-reach and hidden populations for HIV surveillance. AIDS 2005; 19 Suppl 2: S67-72.

20. Heckathorn DD. Respondent-driven sampling II: deriving valid population estimates from chain-referral samples of hidden populations. Social Problems 2002; 49:11-34.

21. Ramirez-Valles J, Heckathorn DD, Vazquez R, Diaz RM, Campbell RT. From networks to populations: the development and application of respondentdriven sampling among IDUs and Latino gay men. AIDS Behav 2005; 9:387-402.

22. Johnston LG, Khanam R, Reza M, Khan SI, Banu S, Alam MS, et al. The effectiveness of respondent driven sampling for recruiting males who have sex with males in Dhaka, Bangladesh. AIDS Behav 2008; 12:294-304.

23. Kalton G. Sampling considerations in research on HIV risk and illness. In: Ostrow DG, Kessler RC, editors. Methodological issues in AIDS behavioral research. New York: Plenum Press; 1993. p. 53-74.

24. Heckathorn DD. Respondent-driven sampling: a new approach to the study of hidden populations. Social Problems 1997; 44:174-99.

25. Centers for Disease Control and Prevention. Increases in unsafe sex and rectal gonorrhea among men who have sex with men: San Francisco, California, 1994-1997. MMWR Morb Mortal Wkly Rep 1999; 48:45-8.

26. Van de Ven P, Prestage G, Crawford J, Grulich A, Kippax S. Sexual risk behaviour increases and is associated with HIV optimism among HIV-negative and HIV-positive gay men in Sydney over the 4 year period to February 2000. AIDS 2000; 14: 2951-3.

27. Nera L. Os invisíveis: dificuldade das ONG para conseguir patrocinadores. Folha de S. Paulo 2005; 28 jun.

28. Ministério da Saúde. AIDS e sustentabilidade: sobre as ações das organizações da sociedade. Brasília: Ministério da Saúde; 2001. (Série C. Projetos, Programas e Relatórios, 45).

29. Bardgett HP, Dixon M, Beeching NJ. Increase in hospital mortality from non-communicable disease and HIV-related conditions in Bulawayo, Zimbabwe, between 1992 and 2000. Trop Doct 2006; 36:129-31.

30. Sackoff JE, Hanna DB, Pfeiffer MR, Torian LV. Causes of death among persons with AIDS in the era of highly active antiretroviral therapy: New York City. Ann Intern Med 2006; 145:397-406. 
31. Halkitis PN, Wilton L, Wolitski RJ, Parsons JT, Hoff CC, Bimbi DS. Barebacking identity among HIVpositive gay and bisexual men: demographic, psychological, and behavioral correlates. AIDS 2005; 19 Suppl 1:S27-35.

32. Mansergh G, Marks G, Colfax GN, Guzman R, Rader M, Buchbinder S. "Barebacking" in a diverse sample of men who have sex with men. AIDS 2002; 16:653-9.

33. Centers for Disease Control and Prevention. Resurgent bacterial sexually transmitted diseases among men who have sex with men: King County, Washington, 1997-1999. MMWR Morb Mortal Wkly Rep 1999; 48:773-7.

34. Truong HM, Kellogg T, Klausner JD, Katz MH, Dilley J, Knapper K, et al. Increases in sexually transmitted infections and sexual risk behaviour without a concurrent increase in HIV incidence among men who have sex with men in San Francisco: a suggestion of HIV serosorting? Sex Transm Infect 2006; 82:461-6.

35. Kim AA, Kent CK, Klausner JD. Increased risk of HIV and sexually transmitted disease transmission among gay or bisexual men who use Viagra, San Francisco 2000-2001. AIDS 2002; 16:1425-8.

36. Boily MC, Godin G, Hogben M, Sherr L, Bastos FI. The impact of the transmission dynamics of the HIV/AIDS epidemic on sexual behaviour: a new hypothesis to explain recent increases in risk taking-behaviour among men who have sex with men. Med Hypotheses 2005; 65:215-26.

37. Brito AM, Sousa JL, Luna CF, Dourado I. Tendência da transmissão vertical de AIDS após terapia anti-retroviral no Brasil. Rev Saúde Pública 2006; 40 Suppl:18-22.

38. Centers for Disease Control and Prevention. Trends in HIV-related risk behaviors among high school students--United States, 1991-2005. MMWR Morb Mortal Wkly Rep 2006; 55:851-4.

39. Waldo CR, McFarland W, Katz MH, MacKellar D, Valleroy LA. Very young gay and bisexual men are at risk for HIV infection: the San Francisco Bay Area Young Men's Survey II. J Acquir Immune Defic Syndr 2000; 24:168-74.

40. Clatts MC, Goldsamt L, Neaigus A, Welle DL. The social course of drug injection and sexual activity among YMSM and other high-risk youth: an agenda for future research. J Urban Health 2003; 80(4 Suppl 3):iii26-39.

41. Stueve A, O'Donnell L, Duran R, San DA, Geier J. Being high and taking sexual risks: findings from a multisite survey of urban young men who have sex with men. AIDS Educ Prev 2002; 14:482-95.

42. Chequer P, VanOss Marín B, Paiva L, Hudes ES, Piazza T, Rodrigues L, et al. AIDS and condoms in Brasilia: a telephone survey. AIDS Educ Prev 1997; 9:472-84.

43. Ritieni A, Moskowitz J, Tholandi M. HIV/AIDS misconceptions among Latinos: findings from a population-based survey of California adults. Health Educ Behav 2008; 35:245-59.
44. Doval AS, Duran R, O'Donnell L, O'Donnell CR. Barriers to condom use in primary and nonprimary relationships among Hispanic STD clinic patients. Hisp J Behav Sci 1995; 17:385-97.

45. Wong CY, Tang CS. Sexual practices and psychosocial correlates of current condom use among Chinese gay men in Hong Kong. Arch Sex Behav 2004; 33:159-67.

46. Szwarcwald CL, Barbosa Júnior A, Pascom AR, Souza Júnior PRB. Pesquisa de conhecimentos, atitudes e práticas na população brasileira de 15-54 anos, 2004. In: Pascom ARP, organizadora. PCAP: pesquisa de conhecimentos, atitudes e práticas na população brasileira 2004. Brasília: Ministério da Saúde; 2006, p. 15-33.

47. Ferreira MP. Conhecimento e percepção de risco sobre o HIV/AIDS: um perfil da população brasileira no ano de 1998. Cad Saúde Pública 2003; 19 Suppl 2:S213-22.

48. Rodrigues-Júnior AL, Castilho EA. A epidemia de AIDS no Brasil, 1991-2000: descrição espaço-temporal. Rev Soc Bras Med Trop 2004; 37:312-7.

49. Corbin WR, Fromme K. Alcohol use and serial monogamy as risks for sexually transmitted diseases in young adults. Health Psychol 2002; 21:229-36.

50. Fan DP. Quantitative estimates for the effects of AIDS public education on HIV infections. Int J Biomed Comput 1993; 33:157-77.

51. Kippax S, Noble J, Prestage G, Crawford JM, Campbell $\mathrm{D}$, Baxter D, et al. Sexual negotiation in the AIDS era: negotiated safety revisited. AIDS 1997; 11:191-7.

52. Eames KT, Keeling MJ. Monogamous networks and the spread of sexually transmitted diseases. Math Biosci 2004; 189:115-30.

53. Reinisch JM, Sanders SA, Hill CA, Ziemba-Davis M. High-risk sexual behavior among heterosexual undergraduates at a Midwestern university. Fam Plann Perspect 1992; 24:116-21.

54. World Health Organization. Guidelines for second generation HIV surveillance. Second generation surveillance for HIV: the next decade. Geneva: World Health Organization; 2000.

55. Semaan S, Lauby J, Liebman J. Street and network sampling in evaluation studies of HIV risk-reduction interventions. AIDS Rev 2002; 4:213-23.

56. Kerr LR. Avaliação de comportamento de populações vulneráveis: propostas de monitoramento [CD-ROM]. In: Anais do 8o Congresso Brasileiro de Saúde Coletiva e 11 Congresso Mundial de Saúde Pública. Rio de Janeiro: ABRASCO; 2006.

57. Joint United Nations Programme on HIV/AIDS. 2006 report on the global AIDS epidemic. http:// www.unaids.org/en/KnowledgeCentre/HIVData/ GlobalReport/2006/ (accessed on 08/Oct/2008).
Submitted on 30/Aug/2007
Final version resubmitted on 12/Jun/2008 Approved on 17/Jun/2008 